\title{
ESTUDO SOBRE A IMPLANTAÇÃO DE UM CENTRO DE CULTURA, ESPORTE E LAZER NA ANTIGA AARP - EM PIRAPOZINHO/SP
}

\author{
Korina Costa, Sidielen Carmen Souza Sobrinho
}

Universidade do Oeste Paulista - UNOESTE, Faculdade de Engenharias e Arquitetura e Urbanismo, Presidente Prudente, SP. E-mail: korina.arq@gmail.com, sidielensobrinho@outlook.com.

\begin{abstract}
RESUMO
A Associação Atlética e Recreativa de Pirapozinho (AARP) foi um antigo clube recreativo da cidade de Pirapozinho - SP que atualmente encontra-se desativado. Nesse artigo será abordado o conceito de centro culturais, ampliando o conhecimento na área de memória e patrimônio arquitetônico e apresentando análises das características da edificação estudada. O principal objetivo do trabalho é entender o processo de degradação do edifico e também de sua memória e propor um novo uso ao local, agora com intuito de lazer e cultura para a população da cidade.

Palavras-chave: Associação Atlética e Recreativa de Pirapozinho, Memória Cultural, Patrimônio Arquitetônico, Centro de Cultura, Pirapozinho-SP.

STUDY ABOUT THE IMPLANTATION OF A CULTURE CENTER, SPORT AND LEISURE IN THE FORMER AARP - IN PIRAPOZINHO / SP
\end{abstract}

\begin{abstract}
The Associação Atlética e Recreativa de Pirapozinho (AARP) was a former recreational club in Pirapozinho - São Paulo state, Brazil, which currently is disabled. In this article discuss the concept of cultural centers, expanding knowledge in architectural heritage area and providing analysis of studied building characteristics. The main objective is understand the degradation process of building and also of their memory, proposing a new use to location, now with the purpose of recreation and culture for the city's population.

Keywords: Associação Atlética e Recreativa de Pirapozinho, Cultural Memory, Architectural Heritage, Culture Center, Pirapozinho.
\end{abstract}




\section{INTRODUÇÃO}

O mundo contemporâneo tem se tornado cada vez mais competitivo, onde a cultura vem sendo abordada como forma de entretenimento por empresários, políticos e agentes culturais. Ela é vista como uma mercadoria "espetacularizada" na imagem da cidade tendo se tornado um "bom negócio". Entretanto, o Centro Cultural é muito mais que isso, ele provoca modificações nos ambientes construídos e pode recuperar, revitalizar e dar uma nova funcionalidade para os espaços considerados degradados. (NEVES, 2013, s/p)

Chamados de centros de arte, os primeiros centros culturais foram criados pelos ingleses no século XIX. Eram espaços privilegiados pelas políticas culturais dos países socialistas europeus no século $X X$, que já manifestavam a prática da ação sociocultural. Mas, foi só no final da década de 50, na França, que foram lançadas as bases do que atualmente entendemos como ação cultural. (COELHO, 1986). Os centros culturais franceses surgiram como uma opção de lazer criada para atender seus operários, o que valorizou o lazer por parte das indústrias e empresas francesas, criando novas relações de trabalho e gerando a necessidade de se criar áreas de convivência, quadras esportivas e centros sociais. (RAMOS, 2007)

Já no Brasil, o interesse por centro cultural surgiu a partir da década de 1960, mas só se efetivou por volta dos anos 1980, e nos últimos anos teve um crescimento gigantesco financiado por investimentos e pelas leis de incentivo à cultura, sendo, atualmente, uma das principais realizações por parte dos órgãos públicos. (RAMOS, 2007)

Para Milanesi (apud NEVES, 2013), o objetivo de um centro cultural é promover a ação cultural através da reunião de um público com características heterogêneas. Assim, Neves (2012, $s / p)$ afirma que é necessário que a relação entre cultura e a realidade da área sejam asseguradas, de modo que se obtenha vínculos com a comunidade e com os acontecimentos locais, "funcionando como um equipamento informacional, no qual proporciona cultura para os diferentes grupos sociais, buscando promover a sua integração". Um centro cultural deve ser, enfim, um pólo de cultura viva, proporcionando ao público, liberdade de se fazer cultura e favorecendo a sua conscientização" (NEVES, 2013, s/p). Uma vez que "constituem o território privilegiado das ações culturais e informacionais na sociedade contemporânea". (RAMOS, 2007, $s / p)$.

Tendo em vista o abandono envolvendo o edifício da AARP, causado pelo desamparado do poder público e incitado pela falta de conhecimento da população sobre a importância do patrimônio histórico e arquitetônico, verifica-se a necessidade de discutir o descaso pela memória do edifício. A necessidade de um centro de cultura que realmente funcione na cidade, somada ao fato de sua implantação ser em um local privilegiado, com fácil a acesso por vários pontos da cidade, torna, a custo benefício, a revitalização da AARP mais viável que a construção a partir do zero de um centro que reúna cultura, lazer e esporte, uma vez que esse espaço já possui um apelo para tal função.

A AARP, Associação Atlética e Recreativa de Pirapozinho, foi uma empresa privada, fundada na década de 1960, que atuava na área de clubes recreativos e esportivos. O Clube foi desativado no início dos anos 2000 e vem se degradando desde então. O descaso com sua preservação nutre o desrespeito pelo patrimônio histórico e cultural do município e fere a memória da cidade. A memória urbana é fundamental na composição identitária de um lugar, ela é elucidada através do patrimônio arquitetônico, uma herança simbólica consolidada no presente, que atua na memória coletiva, resgatando amistosamente o passado. Essa herança simbólica deve ser preservada, uma vez que ela é, além de um exemplar de uma determinada época, um instrumento de rememoração fundamental para toda a sociedade.

A AARP não é um edifício de grande representatividade arquitetônica, mas, por toda a sua história, ambiência e significado, tornou-se de representatividade e significância para a memória da cidade e de sua população, sendo assim, estudá-lo e entendê-lo enquanto local de 
representação histórica da sociedade de Pirapozinho, compreendê-lo dentro de sua atual deficiência e degradação e apresentar direcionamentos para sua futura utilização, mostra a compreensão de que há uma grande potencialidade e a possibilidade de resgate de sua importância para a população da cidade.

Sendo assim, este trabalho é resultado do estudo realizado acerca do atual estado de degradação em que se encontra o edifício da Associação Atlética e Recreativa de Pirapozinho (AARP), cuja finalidade é entender e discutir o processo de degradação da memória e do edifício, e propor a revitalização, não apenas do edifício, mas de toda a área da AARP para o uso de centro de cultura, esporte e lazer da população fomentando a discussão sobre a importância memorial da arquitetura nas cidades e explanar sobre a história da cidade de Pirapozinho, bem como da AARP. Pretende-se também, mapear e discutir sobre os espaços de cultura da cidade, propor soluções projetuais que preservem a concepção urbana e paisagística do local e propor a revitalização da preexistência arquitetônica para que se torne ambiente de convivência entre os moradores, polarizando as atividades de cultura, esporte e lazer do município.

\section{METODOLOGIA}

A presente pesquisa é de cunho qualitativo e foi desenvolvida por meio de investigação bibliográfica através de livros, revistas, artigos científicos e acadêmicos- físicos e virtuais -, e análise de referenciais arquitetônicos, assim como do desenvolvimento de levantamentos in loco da preexistência. Também foram feitos levantamentos dos pontos de cultura presentes no município para entender o motivo da negligência em tais espaços.

Uma vez que o estudo teórico foi concluído, iniciou-se a fase prática, onde foram feitos levantamentos in loco a respeito da área e das medidas da preexistência. O projeto será feito visando estima e comunicação entre intervenção e preexistência, desta forma, pretende-se evitar a demolição total da edificação. Trabalho este que se desenvolveu em decorrência dos apontamentos e procedimentos de pesquisa de Teixeira (2000), que ressalta cada etapa de tal processo e evidencia a significância do olhar do pesquisador para os levantamentos e para a relação entre teoria e análises.

\section{RESULTADO SOBRE A ASSOCIAÇÃO ATLÉTICA E RECREATIVA DE PIRAPOZINHO}

A Associação Atlética e Recreativa de Pirapozinho (AARP), foi uma empresa privada que atuava na área de clubes recreativos e esportivos fundada na década de 1960. Localizada na área central de Pirapozinho - SP, no cruzamento das ruas Castro Alves e Florisvaldo Ribeiro de Bessa, atualmente encontra-se desativada e em processo de degradação, o que incomoda a população por se tratar de um espaço representativo para a história da cidade.

Antigamente, o grande sonho de qualquer cidade em desenvolvimento era ter um clube de lazer, pois caracterizava-se como status e contemplaria àqueles que desejavam dele desfrutar, reunindo amigos, promovendo atividades esportivas, desenvolvendo a cultura e alternando a integração da sociedade como objetivo maior. (MÔNACO, 2012). Assim, João Assef morador da cidade - e um grupo de amigos fundaram a Associação Atlética e Recreativa de Pirapozinho Esporte Clube. Era um espaço privado da qual faziam parte apenas os associados, cuja aquisição de títulos não era acessível a todas as classes sociais. Os não associados só podiam entrar acompanhados de um associado e mediante pagamento de uma taxa de visitante. Na época era o lugar mais badalado da cidade e oferecia atividades como futebol society, futsal, vôlei, basquete, natação e, esporadicamente, bailes festivos. A situação começou a mudar através da mudança de hábitos da população. O lazer em clubes fechados passa a sofrer uma perda de status e prestígio, o que culmina na falta de frequência de associados e, consequentemente, o espaço passa a se ver sem condições de manter a mesma estrutura com uma renda inferior.

Em meio a baixa frequência de associados e, consequentemente, o declínio desse tipo de lazer, os empresários tentaram alternativas para manter a AARP ativa. Nos anos 1990, o 
clube passa a funcionar como boate e torna-se forte na realização de eventos carnavalescos como festas de blocos e matinês. Porém, o novo programa não consegue se manter por muito tempo e, no início dos anos 2000, tem sua função recreativa desativada. Nos anos 2002 o local passa a sediar a Prefeitura Municipal e mantém-se como repartição pública até os anos de 2008, quando é definitivamente fechada. Desde então o espaço encontra-se sem uso regulamentado e sofre forte degradação.

\section{DISCUSSÃO SOBRE APROPRIAÇÃO DA AARP}

Desde que deixou de sediar a Prefeitura Municipal em 2008, a AARP foi apropriada para os mais diversos usos. Sediou por um tempo um projeto social PirAção, relacionado à cultura do hip-hop, e, quando o projeto foi removido para outro prédio pela prefeitura, os frequentadores continuaram por lá, utilizando o espaço para a prática recreativa de skate. Em seguida, parte do local passou a ser utilizado pela Organização Não-Governamental (ONG) S.O.S. Animais para abrigo de animais domésticos abandonados. Os responsáveis pela ONG não apresentaram resistência à presença dos skatistas, e ambos passaram a compartilhar o local.

Percebe-se que a área interna do salão de festas encontra-se relativamente bem cuidada, enquanto que as áreas externas estão deterioradas. Isso se dá pelo fato de que o salão vem sendo utilizado por jovens moradores da cidade de forma improvisada para a prática recreativa de skate, que mesmo sendo uma prática não autorizada, deu-se de forma ordenada, não levando à destruição do patrimônio arquitetônico. A apropriação do local pelos jovens da cidade modificou o caráter do local. O local foi adaptado para a prática de skate e também recebeu grafite em suas paredes. Os atuais usuários do espaço são de todas as idades, desde pré-adolescentes à adultos que tenham algum tipo de ligação com a cena skatista. Apesar de não existir um horário estabelecido, a movimentação geralmente acontece durante o dia na parte da tarde e começo da noite, tendo uma maior frequência nos finais de semana.

Já as áreas externas, estão completamente abandonadas, se deteriorando cada vez mais e abrindo espaço para usuários de drogas, ganhando aspecto de degradação e marginalidade, o que leva aos constantes fechamentos do complexo arquitetônico pela comunidade.

\section{Estudo do terreno}

O terreno localiza-se na região central de Pirapozinho, próximo às principais vias da cidade. Possui $7420,00 \mathrm{~m}^{2}$ de área e pode ser acessado pelas ruas Castro Alves e Florisvaldo Ribeiro de Bessa. A área é predominada pelo uso residencial, havendo também uma considerável quantidade de áreas institucionais. O terreno faz divisa com o Estádio Municipal e fica muito próxima à Escola Estadual Lúcia Silva de Assumpção, à Escola Municipal de Ensino e Instituto Fundamental Moacyr Teixeira e ao Museu Cacique Tibiriçá. Há também um comércio consolidado nas proximidades que atende as demandas de serviços de abastecimento da população de todo o município.

Através do levantamento do gabarito de altura percebe-se que o entorno segue a horizontalidade em sua composição. Constatou-se também que as edificações, em sua maioria, são térreas ou assobradadas, podendo chegar até três pavimentos, não mais que isso.

Quanto aos condicionantes climáticos, a partir da análise da ventilação, foi possível constatar que o vento predominante vem da direção leste e há presença marcante de vegetação. Conforme análise de insolação, constatou-se que a fachada do fundo recebe a maior insolação. Percebe-se também que, apesar do clima quente da cidade, a arborização do entorno consegue manter a temperatura da área mais amena, entretanto, pelo falo de o terreno ser todo murado, cria-se uma barreira que dificulta a ventilação natural no local.

A topografia do terreno tem maior declive em direção aos fundos do lote. As curvas de nível foram modificadas quando a preexistência foi construída, sendo alteradas para que os 
espaços do salão de festas ficassem no mesmo nível e a quadra e o vestiário em outro nível mais abaixo.

O entorno do terreno conta com mobiliário urbano básico: postes de iluminação e energia elétrica, placas de sinalização de trânsito e telefone público, carecendo apenas de lixeiras públicas. Constatou-se que a iluminação artificial do local consegue atender a demanda da área, principalmente por conta de a Escola Lúcia ligar, durante a noite, os refletores de sua quadra.

A área possui equipamentos urbanos de cultura e religião - Igreja Matriz e Museu Cacique Tibiriçá -, segurança pública - Delegacia de Polícia -, esporte e lazer - Praça Manoel Marque Silva e estádio Municipal - e educação - Escola Estadual Lúcia Silva de Assumpção, Escola Municipal de Ensino Infantil e Fundamental Moacyr Teixeira e Colégio Prisma. Uma vez que a ideia é implantar um centro cultural nesta área, tais equipamentos contribuem com as funções de logística urbana e são um fator importante para o bem-estar social do local. A porção onde se situa o terreno da intervenção possui um traçado ortogonal, próximo às principais ruas da cidade: Rua Rui Barbosa e Rua Tiradentes. São vias de configuração clássica: pista central e passeio nas extremidades. A largura dos passeios é de aproximadamente 2,5 metros e das ruas 7 metros, podendo variar um pouco para mais ou para menos.

\section{Barreira Urbana}

Uma vez instituídos no espaço urbano, os muros acabam constituindo barreiras físicas e visuais que isolam os espaços urbanos e causam ruptura da conexão física e visual, interferindo na qualidade estética, funcional e segurança do espaço urbano, pois definem espaços com pouca vigilância natural, sem atrativos para o movimento e a presença de pessoas. (QUINTANA, 2013).

Na AARP, os muros impedem a passagem de pessoas por quase toda sua extensão, sendo então uma barreira física e visual que interrompem a continuidade visual entre rua e edificação. Desta forma, a primeira medida a ser tomada no posterior projeto seria a remoção dos muros preexistentes, afim de deixar a obra mais visível e incorporá-la na paisagem do entorno.

\section{CONCLUSÃO}

Acreditamos que a maior contribuição deste trabalho é a integração das informações no que diz respeito a cultura e patrimônio, para entender o processo de degradação em que se encontra a edificação estudada e ainda, apresentar análises de da preexistência.

Através deste trabalho podemos compreender como o patrimônio cultural, principalmente arquitetônico, é um importante instrumento de rememoração e que influi efetivamente na construção da identidade da cidade. Também podemos atinar sobre a importância da cultura e o papel de centros culturais em nossa sociedade.

Compreendemos ainda que hoje o local estudado, a AARP, encontra-se degradado e que existe uma vontade intrínseca da população de que o local seja recuperado. As análises desenvolvidas neste trabalho apresentam o espaço e traçam direcionamentos a serem considerados na elaboração do projeto final. Assim, em continuidade a esta pesquisa, propomos o desenvolvimento do projeto arquitetônico a partir das diretrizes apresentadas nesse volume.

\section{REFERÊNCIAS}

COELHO, T. O que é ação social. 1. ed. São Paulo: Brasiliense, 1989

MÔNACO, R. Sociedade em declínio: a falência do Clube Social de Camaçari, 2012. Disponível em: < http://www.freellas.com.br/clientes/camacarinoticias/wp/sociedade-em-declinio-a-falencia-doclube-social-de-camacari/> Acesso em: 11 mai. 2016. 
NEVES, R. R. Centro Cultural: a Cultura à promoção da Arquitetura. Revista Especialize On-line IPOG, Goiânia, 5a edição, n. 005, vol. 01/2013, jul.2013. ISSN 2179-5568. Disponível em: <http://www.ipog.edu.br/download-arquivo-site.sp?arquivo=centro-cultural-a-cultura-apromocao-da-arquitetura-31715112.pdf>. Acesso em: 25 nov. 2015.

QUINTANA, E. B. Muros, proteção para quem? Anais: Encontros Nacionais da ANPUR, v. 15, 2013. Disponível em:

http://unuhospedagem.com.br/revista/rbeur/index.php/anais/article/view/4311/4181> Acesso em: 23 abr. 2016.

RAMOS, L. B. Centro Cultural: Território privilegiado na ação cultural e informacional na sociedade contemporânea. Trabalho apresentado no III ENECULT - Encontro de Estudos Multidisciplinares em Cultura, realizado entre os dias 23 a 25 de maio de 2007, na Faculdade de Comunicação/UFBa, Salvador-Bahia-Brasil. Disponível em: <http://www.cult.ufba.br/enecult2007/LucieneBorgesRamos.pdf> Acesso em: 23 nov. 2015.

TEIXEIRA, E. As três metodologias. 2ae ed. São Paulo: Vozes, 2000. 